\title{
A FOURTH METHOD OF CHECKING RESULTS IN VOCATIONAL SELECTION
}

By WALTER DirL Scotr,

Director Bureau of Salesmanship Research, Carnegie Institute of

Technology, Pittsburgh, $\mathrm{Pa}$.

There need be no confusion between vocational guidance and vocational selection. The two are totally distinct in purpose, method of procedure and certainty of results.

The purpose of vocational guidance is to select from all possible vocations that one for which a particular individual is best suited. The purpose of vocational selection is to select for a particular position that one of the applicants who is most likely to succeed in it.

The method of procedure in vocational guidance is to analyze all possible vocations and then to analyze the entire personality of the individual in order that he may be guided into that particular vocation for which he possesses the greatest aptitude or which affords him the greatest possibilities. The method of procedure in vocational selection is to analyze a single vocation, to test applicants as to their fitness for the single function or for the complex of functions involved in this vocation.

The vocational 'guider' has developed no adequate method of checking the certainty or the wisdom of his advice. If he advises Johnny to become a plumber it is quite possible that another equally wise guider would advise against such action. We know nothing of the agreement between the judgments pronounced by each of a group of experienced advisors all working under the same conditions. If he advise Johnny to become a plumber, Johnny may learn the trade, but succeed only indifferently. Such a failure on Johnny's part can not be construed as conclusive evidence against the wisdom of the guider's advice. If Johnny had entered any other trade or profession his failure might have been more disastrous Even if Johnny had succeeded as a plumber the wisdom of the advice of his guider would not be conclusive. Johnny might possibly have had a much greater career if he had been directed to dentistry. This unusual difficulty of checking results in vocational guidance has given increased importance to vocational selection as a field 
for research and for training for those who hope ultimately to advance the cause of vocational guidance.

Before any method of vocational selection is put into practice, its adequacy is easily checked; checks for estimating the value of a series of special tests have been worked out in actual practice. If, for example, the task is to select salesmen for a particular commodity to be sold under recognized conditions, the sales-manager can readily try out the tests in advance by the following method. Let him select from his present force of salesmen working under these conditions ten successful salesmen, ten who are moderately successful and ten who have not been even moderately successful. Let him arrange these thirty in rank order from best to poorest. Let his rank order then be combined with the rankings made independently by two or more executives of the firm who are acquainted with the salesmen and their work. This combined ranking may be spoken of as the Firm Rank, and should agree closely with the rankings of the thirty, secured from the tests, if the tests are dependable. In actual practice a correlation is frequently secured in excess of 75 .

A second device for checking the tests is to have experienced men tested with the applicants. If a man has already proved himself successful in a given position and then is tested with applicants for the position, he should make a good showing if the tests are adequate. Correspondingly, the man who has been thoroughly tried in the position and has failed should not be able to make a good showing if he takes the tests with the applicants. Men of known ability appearing with applicants may be called 'Ringers' and are useful in checking the adequacy of the method of giving the tests.

There is a third check on tests that is the most dependable of all, but which is not available until after the tests have been put into operation. This may be called Vocational Accomplishments and consists in comparing the ratings received in the tests with the later accomplishments in the vocation. No man engaged in vocational selection should rest content in giving any tests that are not being constantly approved by this most crucial of all checks.

The three checks mentioned above are all being successfully used, but each offers certain obstacles. It is sometimes difficult to induce executives to provide the Firm Rank. The star Ringer is compelled to masquerade as a novice. The unsuccessful Ringer is frequently unwilling to take the tests. The reports on the Vocational Accomplishments are unavailable for weeks or even for years. 

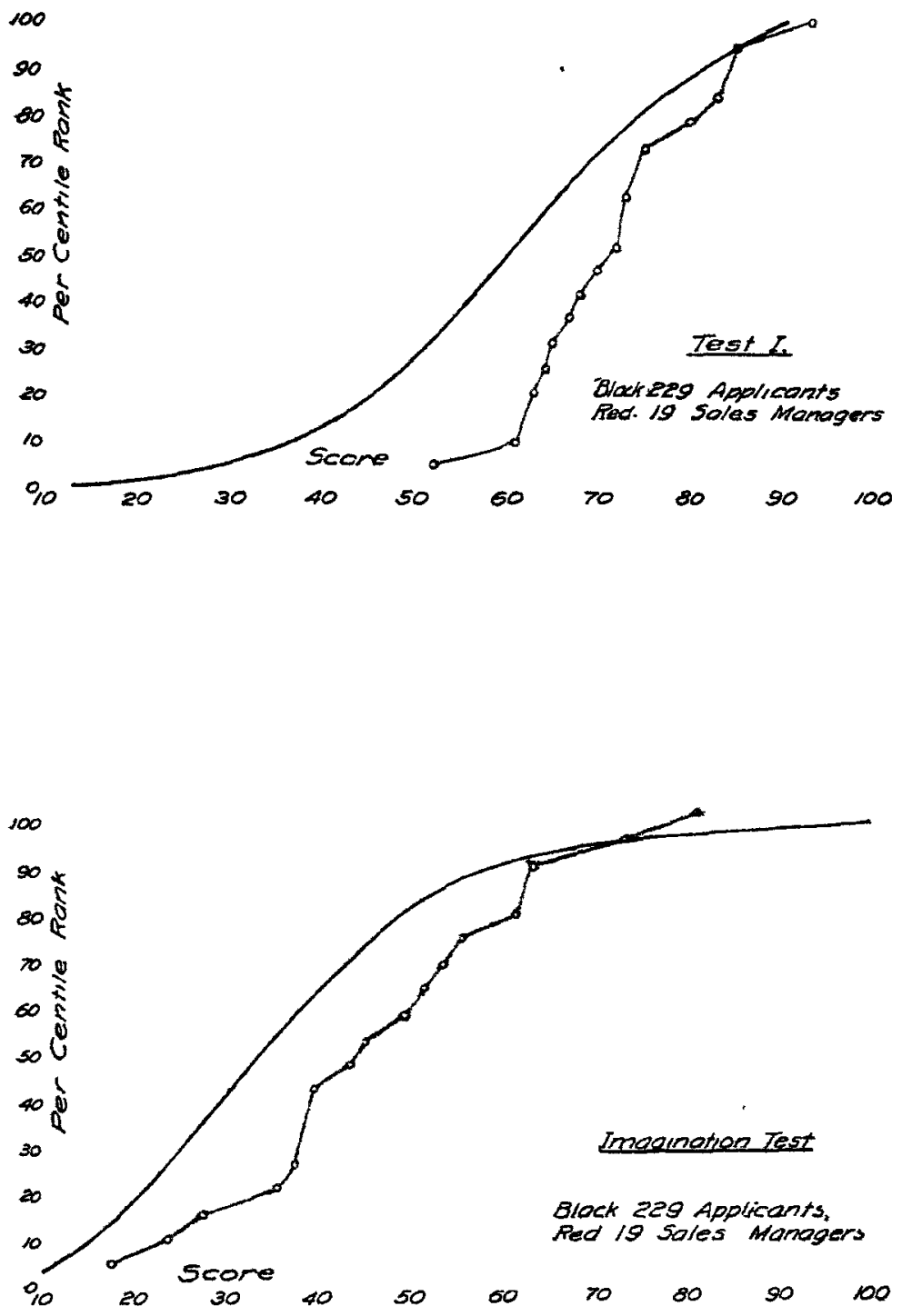

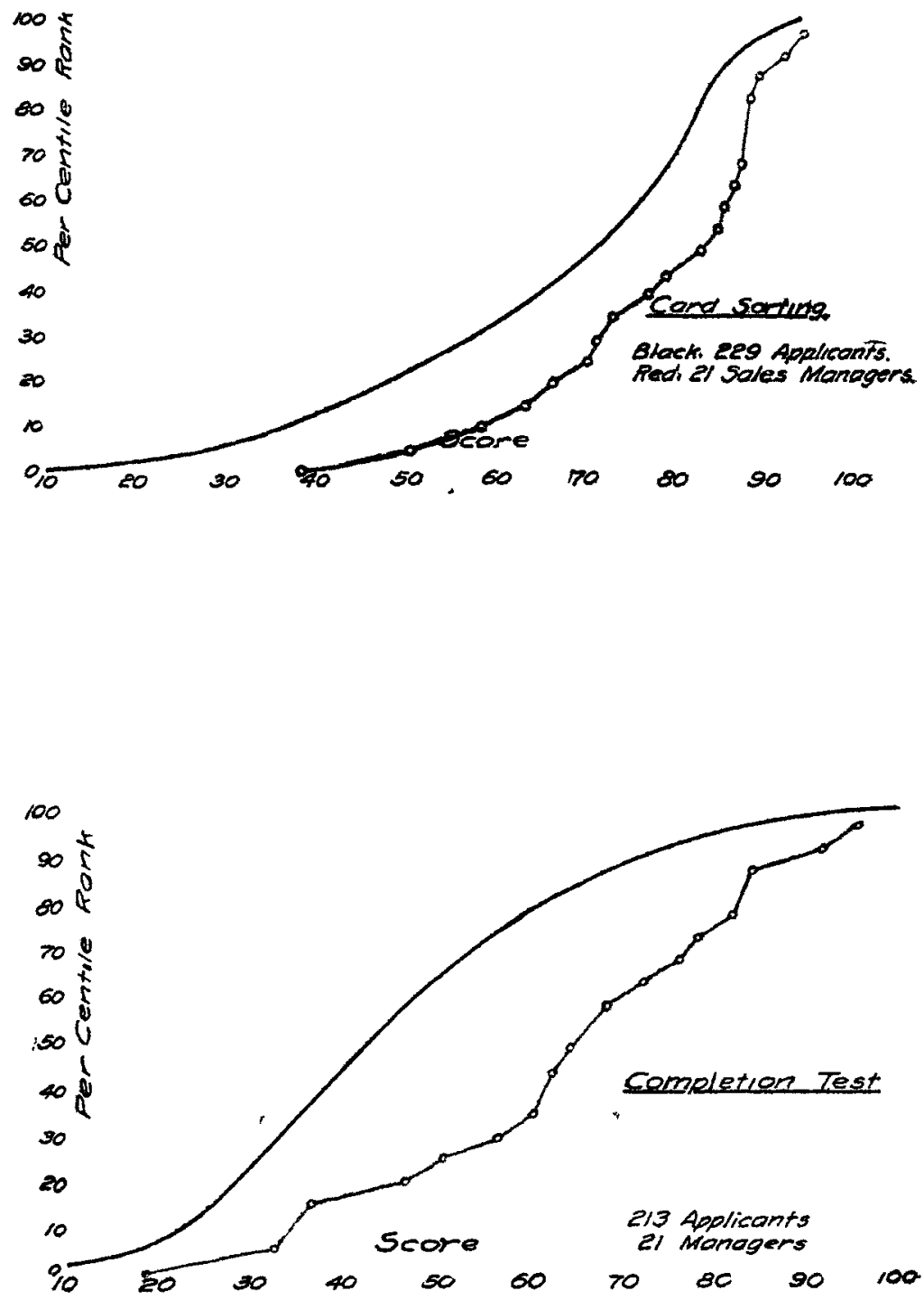


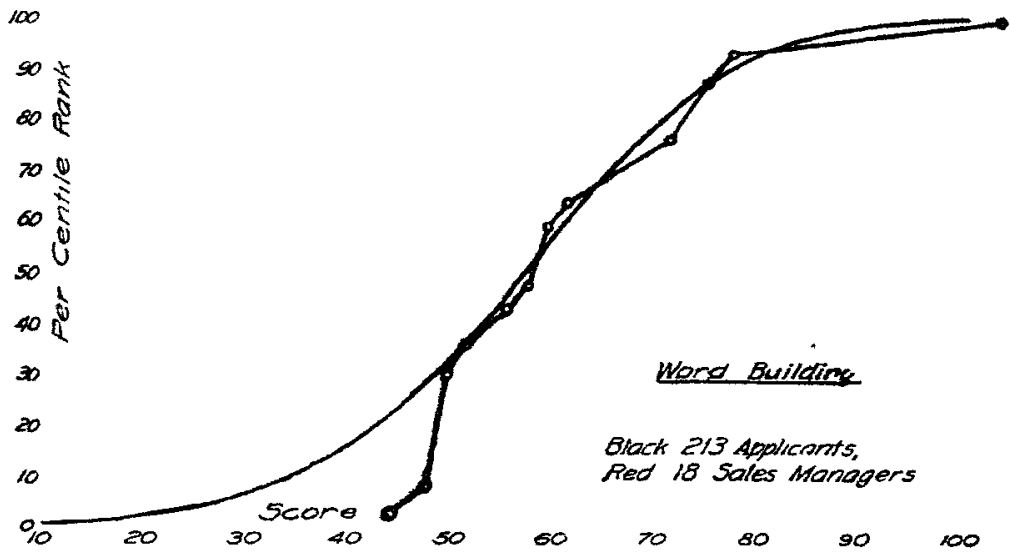

There is a fourth method for checking tests for vocational selection. This method may be designated the Applicants-Experts method. A concrete illustration will make this method clear.

About two hundred and thirty applicants had been recommended for a selling position by the officials of a large selling company. For a period of years about 85 per cent. of all applicants recommended for appointment failed, resigned, or were discharged. It is only fair to assume that these two hundred and thirty men were a typical group, and that 85 per cent. of them, if appointed, would fail. Before appointment the men were all subjected to a series of tests. In the territories where these two hundred and thirty applicants were being tested about twenty 'managers' were induced to take the tests with the applicants. These twenty 'managers' had all succeeded in the task for which the applicants were being sought. The term Applicants as used here refers to that group, 85 per cent, of whom would later fail. The term Experts refers to those who have, at least in a moderate degree, succeeded. The accomplishment of the two groups in the tests is indicated in Charts I to VI. In all the charts the figures on the base line indicate the scores received in the test. The numbers in the vertical column to the left indicate the percentage of the group securing that particular grade or worse. Thus 50 per cent. of the Applicants received in Test I a grade of less than 60 ; only one of the Experts received a grade of less than 60 . 
As will be seen at once from a glance at the charts, each of the tests separated the groups fairly well with the single exception of the Word-Building Test.

The conclusions from this fourth check are obvious. The Word-Building Test fails to differentiate the doubtful from the successful group. Unless there is some reason to the contrary it should be dropped from the battery of tests for this company. Test II is too difficult for either group, but still it differentiates the groups. Tests I, III and IV are very satısfactory in differentiating the groups.

Test $I$ is a test of general intelligence, consisting of opposites, mixed relationship, etc. Test II is an unpublished test of imagination of the constructive type. Test III is a modification of Thorndike's card-sorting test. Test IV is a modification of Trabue's completion test. The WordBuilding test is the well-known Whipple test. In all instances eight tests were given the applicants. Only the five referred to above were given the 'managers'. 